\title{
Aspects of laboratory tests for the determination of the minimum ignition energy of the fuel / dust mixture
}

\author{
Cătălin Mihai POPA $^{1 *}$, Silviu Marin NAN $^{2}$, Mihaela PĂRĂIAN ${ }^{1}$, Adrian JURCA ${ }^{1}$ and \\ Florin $\mathrm{PĂUN}{ }^{1}$ \\ 'The National Institute of Research and Development for Safety in Mines and Explosion Protection, \\ 32-34 G-ral Vasile Milea, Petroşani, România \\ ${ }^{2}$ University of Petroşani, 20 Universităţii street, Petroşani, 332006, Romania
}

\begin{abstract}
During the technological processes of processing, production, handling and storage of combustible dusts, complex explosive mixtures may occur, the characteristics of which, in most cases, cannot be assimilated with the existing data in the specialized literature. If these combustible dusts are mixed with air in appropriate proportions and are initiated by an efficient source of ignition, they can burn rapidly and with considerable explosive force. One of the most common sources of ignition of potentially explosive atmospheres generated by the dust / air mixture is static electricity, materialized by electrostatic discharges. In order to assess the risk of ignition of an explosive mixture of air / dust, it is necessary to know the sensitivity of the explosive atmosphere to ignition, ie the value of the minimum ignition energy of the explosive mixture, which is then compared with the energy resulting from an electrostatic discharge. The paper presents a comparative analysis regarding the methods of determining the minimum ignition energy for air / fuel dust mixtures, using different devices, on the same type of dust.
\end{abstract}

\section{Introduction}

The continuous evolution of human society in recent decades has led to an increase in the need for various products, the realization of which requires the widespread use of chemical compounds in the form of dusts and combustible powders. In technological installations through which these combustible dusts and powders are produced, processed, handled and stored, complex explosive mixtures can frequently occur, which, in most cases, cannot be assimilated with the existing data in the literature specialty.

If these combustible dusts are ignited, they can burn rapidly, and if mixed with air in appropriate proportions, they can lead to explosions with considerable force [1].

Therefore, in order to be able to use technical equipment in conditions of maximum safety, in areas endangered by the presence of explosive air / dust mixtures, it is necessary

\footnotetext{
* Corresponding author: mihai.popa@insemex.ro
} 
to know the type of dust and some parameters that define its sensitivity to ignition with different sources $[2,3]$.

Fig. 1 shows the variety of industries affected by combustible dusts resulted from technological processes specific to each area [4].

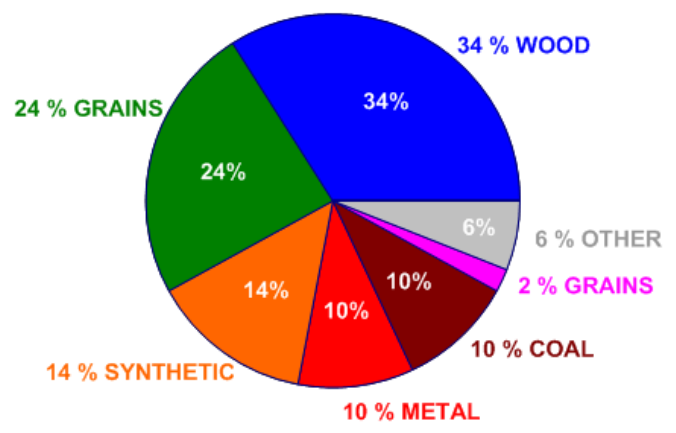

Fig. 1. Variety of combustible dusts in industry

As is well known, in the case of air / dust mixtures, an explosion may occur if the combustible dust is present in the mixture with the explosive air, simultaneously with the appearance or existence of a source of ignition with sufficient ignition energy. In this situation the pentagon of the explosion, shown in figure 2, can be defined [6].

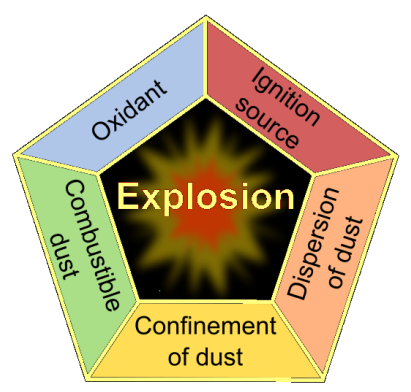

Fig. 2. Pentagon of combustible dust ignition

Electrostatic discharge is one of the most common ignition sources which can initiate an explosive dust / air atmosphere. In order to be able to perform an assessment of the risk of ignition of the explosive dust / air mixture by electrostatic discharges, it is necessary to compare the value of the discharge energy with the value of the minimum ignition energy of the explosive atmosphere formed. Therefore, in the process of assessing the risk of ignition and, implicitly, of identifying and implementing explosion protection measures in the case of dusts or combustible dusts present in technological installations, the knowledge of the ignition energy of these dusts is of particular importance.

The minimum ignition energy (MIE) of an explosive dust / air mixture can be defined as the lowest electric charge stored in a capacitor which at discharge is sufficient to produce an ignition of the most flammable mixture of a given powder under certain specific test conditions. In this paper, a comparative study is performed regarding the methods applied, as well as the devices used to determine the minimum ignition energies for air / combustible dust mixtures, on the same type of dust, by using different devices. 


\section{Theoretical presentation of the methods and devices used to determine the minimum ignition energy}

In the laboratories within INCD INSEMEX Petroşani, the determination of the minimum ignition energy of a combustible dust can be achieved by applying the following methods and the use of their related equipment, as follows:

- Estimation method - for its application it is used as KSEP-20 equipment and estimated values of the minimum ignition energy are obtained;

- Quantitative method - for its application the equipment MIE-D 1.2 with modified Hartmann tube produced by OZM Research - Czech Republic is used, obtaining more accurate values of the minimum ignition energy;

The estimation method is not a standardized method and cannot be applied to any type of dust, as the results obtained for certain combustible dusts are not eloquent. Due to this aspect, in order to obtain the most accurate results in terms of determining the values of the minimum ignition energies of different combustible dusts, in 2018, INCD INSEMEX Petrosani purchased a complex equipment MIE-D 1.2, with modified Hartmann tube, produced by to OZM Research - Czech Republic. After the purchase of this equipment, several tests were performed to determine the minimum ignition energy of combustible dusts, the results being compared with those obtained from the application of the estimation method, finding that not all samples could be compared, as seen in the case presented in point 3 of this paper.

\subsection{Estimated method for determining the minimum ignition energy}

This method consists in recording the combustion time $t_{1}$ relative to different $t_{v}$ delay times with values of $60 \mathrm{~ms}$ and $120 \mathrm{~ms}$, respectively, as defined in figure 3 [3].

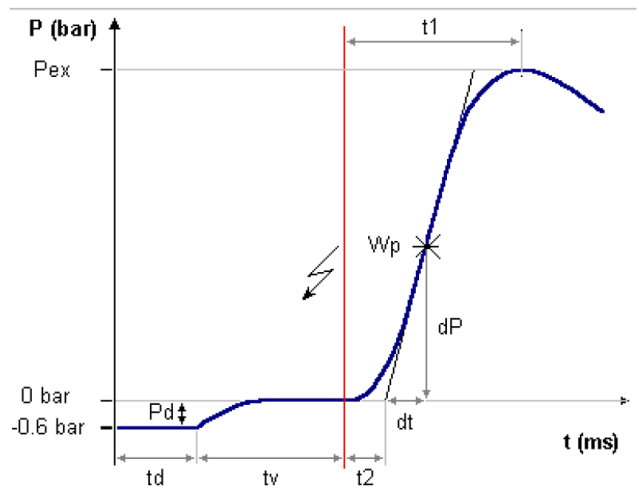

Fig. 3. Pressure / time diagram of an explosion

where:

- $\mathrm{P}_{\mathrm{ex}}$ - explosion overpressure;

$-\mathrm{t}_{1}-$ combustion duration;

- $\mathrm{t}_{2}$ - induction time;

- $\mathrm{P}_{\mathrm{d}}$ - expansion pressure;

- $\mathrm{t}_{\mathrm{d}}$ - output valve delay;

$-t_{v}-$ ignition delay time.

In order to be able to determine the estimated value of the minimum ignition energy, the minimum value for the combustion time $t_{1}$, corresponding to each of the two ignition delay 
times, $60 \mathrm{~ms}$ and $120 \mathrm{~ms}$, respectively, must be determined. When the two series of tests are performed, the lowest value of the combustion time $t_{1}$ in each series is analyzed and it is verified in which of the 4 intervals (as presented in table 1) they fall, thus resulting in the estimated value of minimum ignition energy.

Table 1 - Pairs of correlated values of times $t_{1}$ and $t_{v}$

\begin{tabular}{|c|c|c|c|}
\hline Interval & $\mathrm{t}_{1}, 60(\mathrm{~ms})$ & $\mathrm{t}_{1}, 120(\mathrm{~ms})$ & MIE $(\mathrm{mJ})$ \\
\hline 1 & $<50$ & $<80$ & $<10$ \\
\hline 2 & $50-60$ & $80-95$ & $10-100$ \\
\hline 3 & $61-80$ & $96-120$ & $101-1000$ \\
\hline 4 & $>80$ & $>120$ & $>1000$ \\
\hline
\end{tabular}

The test equipment used to perform this method is KSEP-201, consists in a spherical explosion vessel, explosion resistant, manufactured in stainless steel with a volume of 20 $\mathrm{dm}^{3}$ (see figure 4). For testing, the dust is dispersed in the sphere from the pressurized dust recipient, through a fast-acting valve and a dispersing nozzle. The fast-acting valve is pneumatically open and closed, with the help of an auxiliary piston. The compressed air valves are electrically activated. The ignition source is placed in the center of the sphere [3].
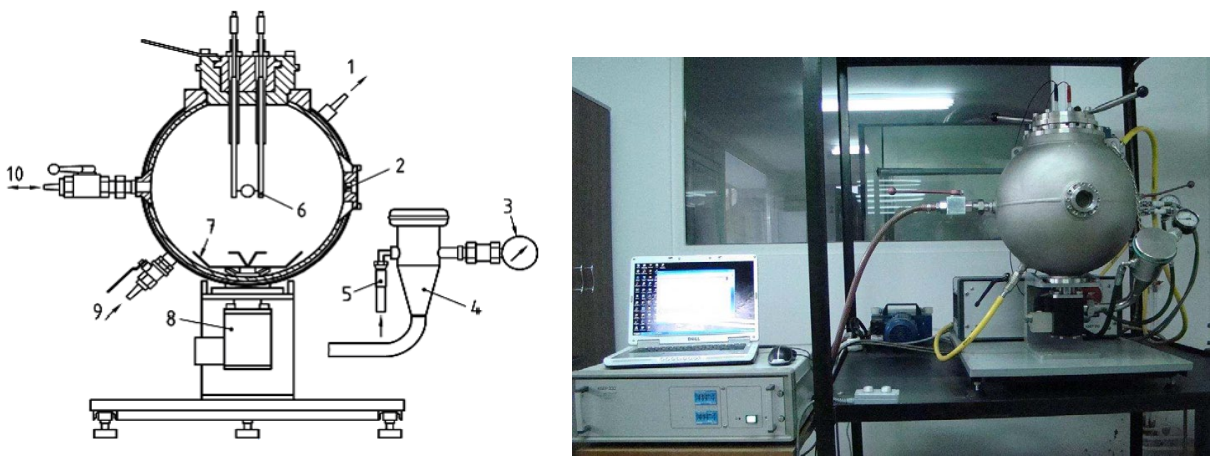

Fig. 4. The KSEP-20 test facility

As it can be seen in Figure 2, the KSEP-20 test facility comprises the following elements: water outlet (1), pressure transducers (2), manometer (3), dust container (4), air intake opening (5), ignition source (6), spray nozzle (7), quick-acting valve (8), inlet for water (9), exhaust outlet (10).

Two piezoelectric pressure transducers are located on the inner wall of the blast vessel and record variations in the explosion pressure produced inside the vessel, after which, using a dedicated interface and software, the data obtained are collected and, based on these data, are generated the necessary graphs to determine the explosive parameters [3].

\subsection{Quantitative method for determining the minimum ignition energy [7]}

In order to be able to implement this method, in 2018, INCD INSEMEX Petrosani purchased a complex equipment MIE-D 1.2, with modified Hartmann tube, produced by OZM Research - Czech Republic, shown in figure 5. 

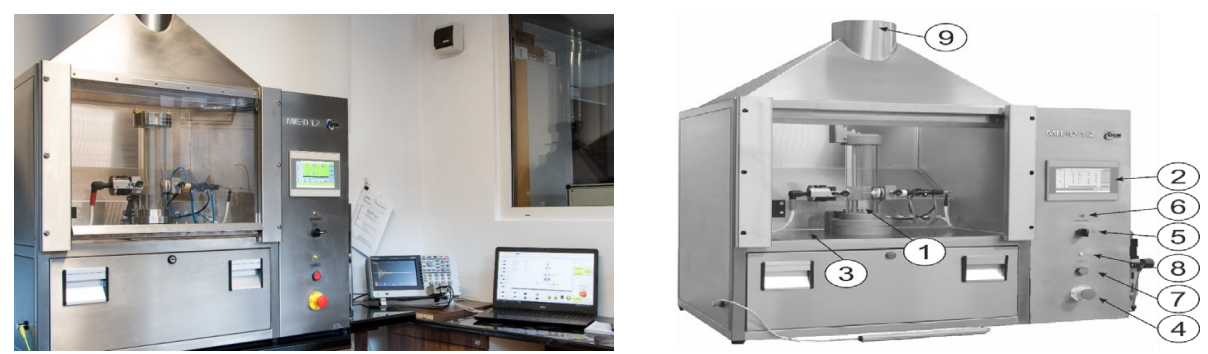

Fig. 5. MIE-D 1.2 equipment

This complex equipment consists of the following main parts: Hartmann glass tube (1), control panel (2), sliding door equipped with a closed-position safety sensor (3), emergency stop button (4), high voltage switch (5), high voltage presence indicator (6), start button (7), function indicator (8), outlet for exhaust fumes (9).

The modified Hartmann tube, which is part of the MIE-D 1.2 equipment, is in the form of an explosion-proof glass container with a volume of 1.2 liters (Figure 6). The dust dispersion system at the base of the tube is of the mushroom type around which the dust sample is freely dispersed. The dust stored at the base of the Hartmann tube is dispersed by a stream of compressed air. The dust dispersed in the glass cylinder is then ignited by an electric spark produced between two electrodes.

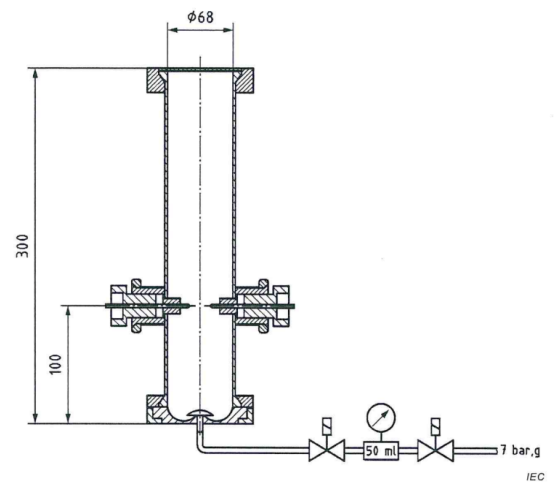

Fig. 6. Modified Hartmann tube

If the energy is less than $10 \mathrm{~mJ}$ the spark is generated by a system consisting of two fixed electrodes (figure 7) and a high voltage relay generation circuit shown in figure 4 . In this electronic circuit, the following are found: $U_{o}$ is charging voltage, $U_{p}$ is discharge voltage, $\mathrm{C}_{\mathrm{o}}$ is electrical storage capacity, $\mathrm{C}_{\mathrm{p}}$ is parasitic electrical capacity, $\mathrm{L}$ represent inductance (additional) and HVR represent high voltage relay.

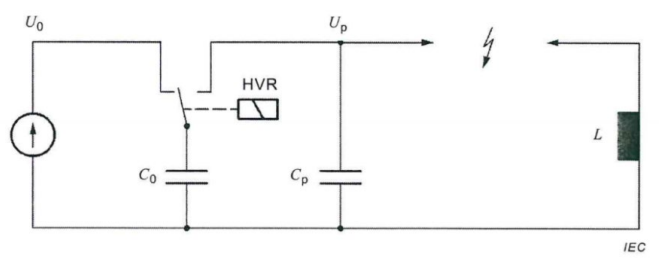

Fig. 7. Two-electrode system and high voltage relay discharge

At very low energies the inevitable parasitic capacity of the electrode assembly has the same order of magnitude as the electrical storage capacity. Therefore, at this stand, the 
parasitic capacity is kept constant and the discharge voltage must be calculated as follows (1):

$$
U_{p}=U_{0} \cdot C_{0} /\left(C_{0}+C_{p}\right)
$$

From here you can calculate the energy of the E spark as (2):

$$
\left.E=0,5 \cdot\left(C_{0}+C_{p}\right) \cdot U_{p 2}\right)
$$

The discharge capacitor $\mathrm{C} 0$ will be charged with a potential equal to (3):

$$
Q_{0}=U_{0} \cdot C_{0}
$$

If the energy is higher than $10 \mathrm{~mJ}$, a system with two electrodes is used to produce the electric spark, one of them being mobile (figure 8).

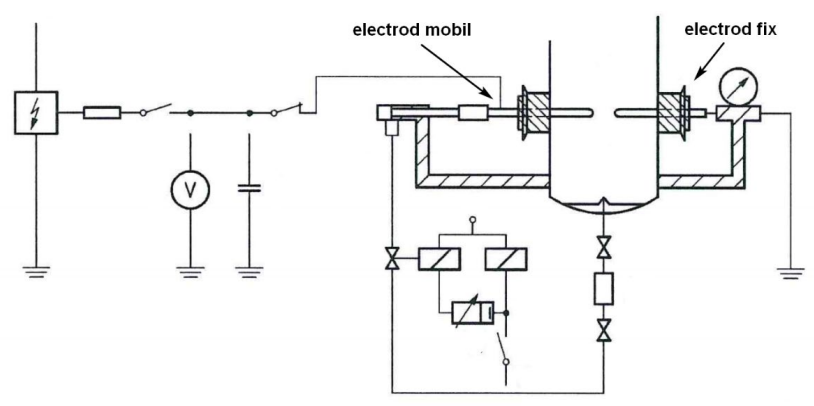

Fig. 8. Hartmann tube modified with a mobile electrode

At start, the mobile electrode is in the initial position. In this position, the gap between the two electrodes is so large that a discharge will never occur. After opening the charging relay, the electrode (ME) is moved rapidly through a pneumatic system to reach the preset minimum distance of $6 \mathrm{~mm}$ between the electrodes. The disruptive discharge occurs before the end position is reached.

The spark energy $\mathrm{E}$ is calculated according to the following formula (4):

$$
E=0,5 \cdot C_{0} \cdot U_{p 2}
$$

\section{Practical determination of the minimum ignition energy for a powder (nystatin) by applying the two methods presented}

In the following, a comparative study is presented regarding the values of the minimum ignition energy obtained by applying the two methods described above in the laboratories belonging to INCD INSEMEX Petrosani, in the case of a sample of atomized mycelium powder (nystatin).

\subsection{Determination of the minimum ignition energy for nystatin by the estimation method}

Applying this method, by recording the combustion time t1, two series of tests were performed in table 2 . 
Table 2 - Combustion time values $\mathrm{t}_{1}$

\begin{tabular}{|c|c|c|c|c|c|}
\hline $\begin{array}{l}\text { Nr. } \\
\text { crt }\end{array}$ & \multicolumn{2}{|c|}{ Sample identification } & $\begin{array}{c}\text { Dust } \\
\text { concentration, } \\
\left(\mathbf{g} \cdot \mathbf{m}^{-3}\right)\end{array}$ & $\begin{array}{l}\text { Delay time } \\
\quad \mathbf{t}_{\mathrm{v}}(\mathrm{ms})\end{array}$ & $\begin{array}{c}\text { Combustion } \\
\text { time } \\
\mathbf{t}_{1}(\mathrm{~ms})\end{array}$ \\
\hline 1 & \multirow{6}{*}{$\begin{array}{l}\text { Atomized mycelium } \\
\text { powder - Nystatin }\end{array}$} & \multirow{3}{*}{$\begin{array}{c}1 \text { series } \\
\text { at } \\
t_{\mathrm{v}}=60 \mathrm{~ms}\end{array}$} & 250 & 60 & 47 \\
\hline 2 & & & 500 & 60 & 36 \\
\hline 3 & & & 750 & 60 & 36 \\
\hline 4 & & \multirow{3}{*}{$\begin{array}{c}2 \text { series } \\
\text { at } \\
t_{\mathrm{v}}=120 \mathrm{~ms}\end{array}$} & 500 & 120 & 60 \\
\hline 5 & & & 750 & 120 & 73 \\
\hline 6 & & & 1000 & 120 & 56 \\
\hline
\end{tabular}

Analyzing the lowest value of combustion time $t_{1}$ in each series $-t_{1}=36 \mathrm{~ms}$ at delay time $t_{v}=60 \mathrm{~ms}$ in the first series and $\mathrm{t}_{1}=56 \mathrm{~ms}$ at $\mathrm{t}_{\mathrm{v}}=120 \mathrm{~ms}$ in the second series - and comparing with the reference values in Table 1, the minimum ignition energy range for the analyzed dust can be deduced to be less than $10 \mathrm{~mJ}$.

\begin{tabular}{|c|c|c|c|}
\hline Interval & $\mathrm{t} 1,60(\mathrm{~ms})$ & $\mathrm{t} 1,120(\mathrm{~ms})$ & $\mathrm{MIE}(\mathrm{mJ})$ \\
\hline 1 & $<50$ & $<80$ & $<10$ \\
\hline
\end{tabular}

\subsection{Determination of the minimum ignition energy for nystatin by the quantitative method}

The combustible dust (nystatin) to be tested is uniformly dispersed in the air at room temperature and pressure. After the dust / air mixture is made, it is subjected to a spark discharge, which comes from a charged capacitor..

Given that the minimum level of dust turbulence and its optimal concentration cannot be obtained in a single step, the process of determining the minimum ignition energy is carried out by going through several stages, as follows:

Stage 1: At the beginning, a value of the minimum ignition energy is chosen which will lead to the safe ignition of the dust under test, the concentration of which in the air is known. The value of the spark energy is gradually decreased (for example by $50 \%$ ) at the given dust concentration until the dust / air mixture formed no longer ignites in any of the 10 tests at a certain energy value..

Stage 2: The procedure is then continued by varying the dust concentration $(200 \mathrm{mg}$, $400 \mathrm{mg}, 600 \mathrm{mg}, 800 \mathrm{mg}, 1000 \mathrm{mg}$ and $1200 \mathrm{mg}$ ) to the lowest value of the minimum ignition energy determined in step 1 . If an ignition at a certain concentration of dust occurs, step 1 is repeated for that concentration.

Stage 3: The procedure with this combination of spark energy and dust concentration, changing the delay time until the maximum energy $\left(E_{1}\right)$ at which no ignition occurs is determined.

The minimum ignition energy, $E_{\min }(\mathrm{MIE})$ is between the highest value of energy $\mathrm{E}_{1}$ at which no ignition occurred during 10 consecutive attempts to ignite the air / dust mixture and the lowest energy value $E_{2}$, when at least one ignition occurred during the 10 consecutive attempts.

$$
E_{1}<M I E<E_{2}
$$

For our case, following the steps above, it turned out that the value of the minimum ignition energy is: 
namely,

- the highest energy at which ignition does not occur, $\mathrm{E}_{1}=100 \mathrm{~mJ}$;

- the lowest energy at which ignition occurs, $\mathrm{E}_{2}=300 \mathrm{~mJ}$.

Minimum ignition energies can be determined using a variety of equipment and / or test procedures. For the purpose of comparing different equipment, only one value for $\mathrm{E}_{\mathrm{s}}$ should be used instead of an energy range $\left(E_{1}, E_{2}\right)$. This value $E_{s}$ can be calculated using the ignition probability as follows:

Assuming that the energy $E_{2}$ has been tested to at least 5 equally spaced dust concentrations, the position $\mathrm{E}_{\mathrm{s}}$ can be estimated in the range $\mathrm{E}_{1} \ldots \mathrm{E}_{2}$. The exponent of the equation below, after the initial energy $\mathrm{E}_{2}$, the number of ignition dust concentrations (I $\left.\left[\mathrm{E}_{2}\right]\right)$ is divided by the total number of dust concentrations $(\mathrm{NI}+\mathrm{I})\left[\mathrm{E}_{2}\right]$.

$$
E_{S}=10^{\log \left[E_{2}\right] \frac{I\left[E_{2}\right] \cdot\left(\log E_{2}-\log E_{1}\right)}{(N I+I) \cdot\left[E_{2}\right]+1}}
$$

In our case the value resulted from the teste are presented in table 3:

Table 3 - Probability of ignition

\begin{tabular}{|l|c|c|c|c|c|c|c|c|}
\hline & \multicolumn{7}{|c|}{ Concentrations [mg] } & \multicolumn{2}{c|}{$\begin{array}{c}\text { Probability of } \\
\text { ignition }\end{array}$} \\
\hline & 200 & 400 & 600 & 800 & 1000 & 1200 & I & NI+I \\
\hline $\begin{array}{l}\mathrm{E}_{2}=300 \mathrm{~m} \\
\mathrm{~J}\end{array}$ & 0 & 1 & 2 & 2 & 3 & 1 & 5 & 6 \\
\hline $\begin{array}{l}\mathrm{E}_{1}=100 \mathrm{~m} \\
\mathrm{~J}\end{array}$ & 0 & 0 & 0 & 0 & 0 & 0 & & \\
\hline
\end{tabular}

where:

I means ignition

NI means without ignition 10 times

The result in our case was calculated according to the equation mentioned above, the value of energy $\mathrm{E}_{\mathrm{s}}$ being $137 \mathrm{~mJ}$.

\section{Conclusions}

In order to assess the risk of ignition of an explosive air / dust mixture, it is necessary to know the minimum ignition energy of that fuel dust.

Knowing the value of the minimum ignition energy (MIE) of the combustible dust that in mixture with the air can lead to the appearance of potentially explosive atmospheres, a series of protection / prevention measures can be adopted and implemented depending on the nature of the technological process carried out.

The paper presents two methods for determining the minimum ignition energy of combustible dusts, applied in INCD INSEMEX Petrosani laboratories, using different equipment, on the same sample of nystatin powder, with the same granulation and humidity.

The basic principle in the case of the first method is to record the combustion time at different delay times, while in the case of the second method the basic principle is to initiate the dust / air mixture by an electric spark produced between two electrodes.

Analyzing the results obtained by applying the two methods, we can conclude that the results obtained from the application of the quantitative method are more accurate, given 
the principle of the method, and should be used to establish protection measures to prevent the initiation of explosive dust / air mixtures and to ensure their repeatability in different test laboratories.

The estimation method can be used as a method of interpreting the minimum energy, but still the standardized (quantitative) method is currently the reference method in determining the minimum ignition energy.

\section{References}

1. A. Jurca, F. Păun, M. Părăian, D. Gabor, L. Lupu, Proceedings of the 18th International Multidisciplinary Scientific Geoconference SGEM 2018 18, 819-826, (2018)

2. Directive 2014/34/EU (2014)

3. A. Jurca, D. Gabor, F. Păun, N. Vătavu, M. Părăian, Comparative study having in view the methods of determination the minimum ignition energy of the air/combustible dust mixtures, 19th International Multidisciplinary Scientific Geoconference (2019)

4. A. Jurca, C. Lupu, M. Părăian, N. Vătavu, F.T. Iacob-Ridzi, The importance of determining explosivity parameters of combustible dusts, Environmental Engineering and Management Journal 13, 1535-1545, (2014)

5. M. Popa., S. M. Nan, M. Părăian, A. Jurca, F. Păun, L. Lupu, N. Vătavu, D. Gabor, Study of explosive characteristics of combustible powders, 8th International Multidisciplinary Scientific Symposium ,, UNIVERSITARIA SIMPRO” ISSN-L 1842 - 4449, ISSN 2344 - 4754 (2018)

6. A. Jurca, E. Ghicioi, M. Părăian, S. Burian, M. Darie, S. Sicoi, F. Păun, Implementation and carrying out of laboratory test stands required for conformity assessment of equipment intended for use in potentially explosive atmospheres generated by combustible dusts - IRECEEX, INSEMEX Petroşani, (Romanian) C 43/2005, (2005)

7. *** EN ISO/IEC 80079-20-2 (2016) 